\title{
How California agricultural producers manage risk
}

\author{
Steven C. Blank D Jeffrey McDonald
}

\begin{abstract}
In a statewide survey, California agricultural producers ranked output price and input cost highest among their production and financial risks. Due to poor availability of hedging, forward contracting and crop insurance, less than $25 \%$ of the respondents used these tools to reduce risk. Diversification of production or income sources was their most common strategy for managing risk. Until risk tools are better tailored to the needs of California producers, and until producers become better informed about managing income risk, the state's agricultural sector will face unnecessarily high levels of financial stress.
\end{abstract}

During the past 5 years, agricultural lenders have changed their lending procedures; they now place more emphasis on risk analysis, forcing California producers to be more conscious of risk-management decisions ( $\mathrm{J}$. Agri. Lending, Vol. 7, No. 2). As a result, lenders and producers have a heightened awareness of risk issues as they pertain to any particular producer's operation (Financing Agriculture in California's New Risk Environment). Of course, within an individual operation only certain risk sources exist, and only a few of those are of major concern to the producer. Yet it is important for producers to be aware of the particular sources of risk that affect their operations and to be familiar with the tools available to aid in managing these sources of risk.

The primary type of risk that all producers face is the uncertainty of income levels from year to year. This risk is a function of variability in output and input prices, yield and production units (acres, cows, hens and so on). It is important for producers to pay attention to income risk because of the recent and increasing trend among lending institutions to evaluate the borrower's income risk. This increased lender attention to risk may lead to tighter restrictions on the availability of credit to producers. Thus risk management affects the economic survival of an agricultural operation.

This article aims to identify sources of risk that California producers face, to discuss available risk-management tools and their current use, and to explore how California producers can make better use of these tools. To gather this information, we mailed a survey to a random sample of 2,091 California agricultural producers in 1992-1993. This article summarizes the results of that survey to which 569 responded.

\section{Producers' risk attitudes}

The first goal of the survey was to gain perspective on the current attitudes of California producers toward risk. The responses to several questions indicate that producers are now more aware of risk concerns in their operations than they were 5 years ago. Producers were asked which sources of risk concerned them personally and to rank them in order of importance. Production risk concerns, such as pests, drought, floods, freeze and labor availability, are second to financial risk concerns, such as output price, physical factor input cost and labor cost (table 1). California producers ranked output price first and input costs second among their risk concerns.

Producers responding to the survey said that they have become more aware of risk issues in recent years, and that they want to better manage certain risk sources. However, only slight increases are evident in the use of some of the more direct risk-management tools (such as hedging and crop insurance) over the past 3 to 5 years. Although the desire to employ these management tools appears to be growing, there are barriers to the pro-

\begin{tabular}{|c|c|c|c|c|c|c|c|c|c|}
\hline \multirow[b]{3}{*}{$\begin{array}{l}\text { Sources } \\
\text { of risk }\end{array}$} & 1. Sc & es of & and & $\begin{array}{l}\text { agric } \\
\text { spor }\end{array}$ & $\begin{array}{l}\text { ral pr } \\
\text { ts tot }\end{array}$ & ers $r$ & their & rtan & \\
\hline & \multicolumn{8}{|c|}{ Rank } & \multirow[b]{2}{*}{$\begin{array}{l}\text { No. of } \\
\text { responses }\end{array}$} \\
\hline & $1 \mathrm{st}$ & 2nd & 3 rd & 4th & 5th & 6 th & 7 th & 8th & \\
\hline \multicolumn{10}{|c|}{$\%$. } \\
\hline Disease & 16.6 & 17.0 & 13.1 & 16.3 & 14.0 & 11.2 & 8.8 & 3.0 & 465 \\
\hline Drought & 25.5 & 15.7 & 11.9 & 8.9 & 9.4 & 10.2 & 11.7 & 6.6 & 470 \\
\hline Floods & 1.5 & 6.6 & 3.3 & 3.9 & 3.6 & 6.3 & 13.5 & 61.3 & 333 \\
\hline Freeze & 19.9 & 16.8 & 8.9 & 7.6 & 7.8 & 11.2 & 14.8 & 13.0 & 447 \\
\hline Input cost & 12.5 & 21.3 & 21.1 & 13.6 & 14.9 & 9.7 & 4.6 & 2.2 & 445 \\
\hline Labor cost & 8.9 & 12.4 & 13.5 & 13.1 & 15.7 & 16.9 & 11.3 & 8.2 & 451 \\
\hline Output price & 32.0 & 25.9 & 14.6 & 11.1 & 7.1 & 4.4 & 2.9 & 1.9 & 478 \\
\hline Pests & 12.4 & 17.9 & 20.4 & 14.3 & 17.2 & 8.8 & 5.9 & 3.2 & 476 \\
\hline Other* & 35.6 & 15.6 & 13.3 & 17.8 & 6.7 & 2.2 & 2.2 & 6.7 & 45 \\
\hline Govt. regs* & 41.9 & 19.4 & 12.9 & 12.9 & 3.2 & 0.0 & 3.2 & 6.5 & 31 \\
\hline Comp/Trade ${ }^{*}$ & 66.7 & 0.0 & 0.0 & 33.3 & 0.0 & 0.0 & 0.0 & 0.0 & 3 \\
\hline Weather* & 47.2 & 25.0 & 13.9 & 8.3 & 5.6 & 0.0 & 0.0 & 0.0 & 36 \\
\hline \multicolumn{10}{|c|}{$\begin{array}{l}\text { Note: The first column lists a source of risk. The next eight columns list the percentage of respondents } \\
\text { who ranked that source of risk as most important, second most important, and so on. The percentages in } \\
\text { each row are calculated on the total number of respondents citing that risk as a concern listed in the last } \\
\text { column. }\end{array}$} \\
\hline \multicolumn{10}{|c|}{ "Write-in responses. } \\
\hline
\end{tabular}


ducers' ability to do so. The survey results lead to the conclusion that California producers are concerned with the financial risks their operations face and want alternatives for managing those risks. However, there are problems with these tools, as explained in the next section.

\section{Use of risk-management tools}

Faced with lenders' increasing concerns about various risk sources, California producers must choose among existing alternative risk-management tools for both production and financial risk. These tools vary not only in the source of risk they target, but also in their availability and in their degree of impact on the problem. Some of the more direct approaches to risk management are forward contracting, hedging and crop insurance. Although these tools directly affect their respective target risk sources (price variability or yield variability), none are widely available across crops or livestock commodities. Other tools such as enterprise diversification are widely available, but offer somewhat less direct effects on their respective target risk sources.

A small minority of the producers responding to the survey use each of the more direct risk-management tools (crop insurance, government programs, forward contracting and hedging), while nearly half $(47.6 \%)$ of all producers use the less direct tool of diversification (table 2 ). To explain the differences in the levels of use between risk tools, the following sections discuss the major tools and specific responses from producers.

\section{Hedging}

Hedging is a direct approach to price risk management, but it is one of the least available tools. For producers, hedging involves selling a commodity in a futures or options market prior to the date at which the actual commodity will be sold in a cash market. The purpose of hedging is to protect the value of the current cash inventory from possible reductions in price. Therefore hedging is a type of forward contracting that reduces price risk. Unfortunately, it is impossible to hedge if a futures or options market does not exist for the commodity held by the producer. Because futures and options markets are available for only a few of California's products, such as cattle, cotton, orange juice, rice and grains, only some California producers can make use of this risk-management tool.

Of producers who responded to the questionnaire, $6.2 \%$ currently use hedging as a price risk-management tool, while $6.0 \%$ hedged 5 years ago. The current average of output hedged is $16.8 \%$. When asked why they do or do not use futures markets, producers most frequently responded that such markets are not available for their particular commodities. Several re-

sponded that they use futures markets to lock in prices and reduce risk, while others reported that they don't use hedging because they have a bad opinion of futures or don't understand how to hedge. Overall, the dominant reasons for non-use were lack of availability and understanding.

\section{Forward contracting}

As a price risk-management tool, forward contracting is much more available than hedging to California producers. It is comparable to hedging only in that it enables producers to lock in a price for goods to be sold in cash markets in the future. It does not require that a formal futures market exist for a particular crop. Forward contracts are cash market deals that set the terms (price and quantity range) in advance of actual delivery. These contracts may be drawn up between any combination of producers and sellers and may include any terms agreeable to both. The availability of this type of tool is limited only by the individual's ability to find a trading partner. This

\begin{tabular}{|c|c|}
\hline \multicolumn{2}{|c|}{$\begin{array}{c}\text { TABLE 2. Producers' current use of risk } \\
\text { management tools }\end{array}$} \\
\hline Risk management tool & $\%$ producers using ${ }^{*}$ \\
\hline Crop insurance & 24.4 \\
\hline Diversification & 47.6 \\
\hline Forward contracting & 23.4 \\
\hline Government programs & 20.0 \\
\hline Hedging & 6.2 \\
\hline Labor contract & 1.2 \\
\hline Other & 10.9 \\
\hline
\end{tabular}

particular price risk-management tool is quite flexible and notably more available than hedging. Furthermore, its scope is not limited to prices, but can extend to contracts that specify quantities as well. Therefore it is possible for a producer to forward contract in both input and output markets, locking in prices and quantities, thereby eliminating a large portion of the financial risk.

More than $23 \%$ of the producers who responded are currently using forward contracts, considerably more than the $6.2 \%$ who hedge. This difference may be attributed to both availability and perception. As mentioned earlier, there are fewer barriers to using forward contracts than there are to hedging. Another factor that plays an important role in the use of a tool is understanding. Some producers reported that they are not familiar with hedging; although the tool is available, they don't feel comfortable using it to manage price risk in their operations.

Because hedging and forward contracting are both price risk-management tools, some people may consider them to be substitutes for one another. We performed regression analysis on the survey data to help uncover the actual relationship between these tools. As it turns out, these two forms of risk management appear complementary: producers don't tend to use hedging in place of forward contracts, or vice versa. Instead producers who use hedging tend to use forward contracts as well. The rationale for this seems to be twofold. First, hedging may be considered a more short-term price riskmanagement tool, while forward contracts can be used to lock in prices for the long term. Second, given the shortterm/long-term relationship between these two tools, producers who are concerned with price risk and use hedging for short-run risk may also be conscious of long-run risk exposure and choose to employ forward contracts as well. So it can be said that forward contracts and hedging complement each other because they target somewhat different types of price risk.

\section{Crop insurance}

The direct approach to dampening the effect of season-to-season yield 
variability on revenue variability is to purchase crop insurance. Crop insurance is available only for some crops, and the policy terms offered are predetermined by the Federal Crop Insurance Corporation (FCIC). Furthermore, the loss thresholds established by the FCIC for individual crops are designed primarily for farmers in the Midwest, thereby making insurance economically unattractive for many California producers because of the lower levels of yield variability here. One survey question asked farmers to report their largest yield drop in the last 3 years (as compared to average yields). The results show that $55.8 \%$ of producers did not experience a loss exceeding $25 \%$ of average yields, meaning that they would not collect any indemnities on crop insurance under the established loss thresholds. Also, just $26.1 \%$ of producers experienced a loss of more than $35 \%$ of average yields.

Only $23 \%$ of the producers surveyed use crop insurance as a yield risk-management tool, but this is a significant increase over the $16 \%$ of producers who said they had crop insurance 5 years ago. The range of crops insured is broad, and it is clear that crop insurance is more attractive for some crops than for others. For example, almond growers insure the most frequently as a group, while cotton growers choose not to insure, and hedge instead.

Of growers who do use crop insurance, the average coverage is $77.9 \%$ of the anticipated crop acreage. A majority of the respondents $(60 \%)$ who purchase crop insurance stated that they purchase it almost every year. Many (34.6\%) purchase crop insurance in anticipation of particular weather conditions that may harm yields, while $19.7 \%$ state their reason as a safeguard for recovering input costs. Surprisingly, only $8.7 \%$ claim that their loan or financing institution requires the purchase of crop insurance.

The combination of policy premiums and high loss thresholds can be enough to make crop insurance financially unattractive for certain crops, forcing growers to turn to other riskmanagement tools such as diversification. Many producers commented that they would consider purchasing crop

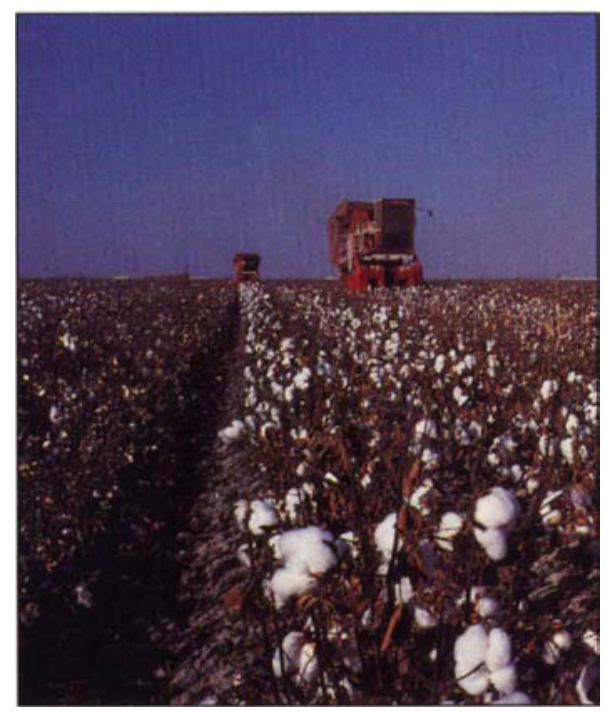

Crop insurance is more attractive for some crops than others. Cotton growers prefer to hedge on the futures or options market.

insurance if it were offered for their major crop, while others mentioned that premiums are too high and that the losses they have experienced do not justify the purchase of crop insurance, given the premiums and loss thresholds offered. Lowering premiums and offering more complete coverage of more commodities were the top suggestions for improvements to the crop insurance program. From the comments on the survey, it is clear that crop insurance is too restricted in availability and not necessarily a "good deal" for many California producers who grow an insurable crop.

\section{Diversification}

Although less formally defined than other tools, diversification is undoubtedly the most readily available risk-management tool. It simply involves deriving income from two or more products or activities at the same time. A diversification strategy can be quite effective in allowing a producer to reduce the overall variance of revenue from year to year, which is the main concern in risk management.

The survey addresses two general types of diversification: diversification of income sources and diversification of operations.

Diversification of income sources typically means that a producer does not rely entirely on income derived from agricultural sources. A typical example is a producer or a family member, such as a spouse, who is employed outside of agriculture. This effectively lowers the variance of revenue to the family by providing a steady income regardless of the success of agricultural enterprises in a given season. The survey revealed that $63 \%$ of producers receive nonagricultural income, representing an average of $47 \%$ of their total family income.

The second type of diversification, diversification in operations, is a more general form that entails producing two or more crop or livestock enterprises at the same time so that a loss in one enterprise is offset by income from others. More generally, diversification amounts to using alternative income sources, such as off-farm income and crop diversity, to lessen the variability of annual income over time.

In the survey, $47 \%$ of the producers indicated that they currently practice some form of diversification, up from $40 \%$ five years ago. Diversification was by far the most popular risk-management tool and was often used in conjunction with other risk tools.

\section{Implications for decision making}

One of our goals is to report the current level of use of risk-management tools by California producers and to offer suggestions about how producers can make better use of these tools. We found that producers who make the best use of risk-management tools are aware of three items:

1. The sources of risk that are contributing most to the producer's income variability;

2. The risk-management tools that are available, given the producer's enterprise composition; and

3 . How the available risk-management tools operate and how they are used.

The following example illustrates the use of risk-management tools, given different sources of risk and the limited availability of risk-management tools in California.

California cotton growers have access to a number of tools for reducing the effects of risk sources on their income, including crop insurance, forward contracting, hedging with futures or options markets, diversifica- 
tion and government programs. Statistical analysis of cotton revenue over time reveals price variability to be the primary source of income risk, while yield variability contributed very little to income risk. The proper choice of risk-management tools then targets price risk rather than yield risk. The two tools that focus on price risk are hedging and forward contracting. The survey results show that $25 \%$ of cotton growers use hedging as a risk-management tool, while only $1.6 \%$ report using crop insurance. This illustrates that producers make appropriate choices among risk-management tools when the source of risk has been identified and several risk-management alternatives exist.

\section{Awareness increasing}

Awareness of risk issues is increasing among California producers. Although producers regard many sources of risk as relevant, it appears from their responses that the attention of lenders is making financial risk paramount among the current risk concerns. The tools available to producers to help manage particular risk sources vary in their effectiveness and availability, and therefore in popularity of use. Many producers indicated that they would be interested in using some of the less available tools, such as hedging and crop insurance, if the tools were available for their crop or livestock enterprise. This indicates latent demand for these tools.

The limited availability of effective risk-management tools severely limits many producers' ability to mitigate risk. At a time when California producers as a whole are becoming more aware of risk concerns, this shortage poses obstacles to risk management. Until tools like crop insurance and futures markets are better tailored to the needs of producers in California, and until producers become better informed about managing income risk, the state's agricultural sector will face unnecessarily high levels of financial stress.

S.C. Blank is Extension Economist and J. McDonald is Research Assistant, Department of Agricultural Economics, UC Davis.

\title{
Vertical drainage may improve soil salinity and moisture
}

\author{
Abdul Karim Yusufzai \ Mark E. Grismer
}

Existing drainage systems in many clay fields of the Imperial Valley have failed to improve soil salinity and to provide moisture conditions favorable to crop growth. In some fields, these problems are exacerbated by saline artesian water from a shallow sand aquifer. This pilotscale field study in the Imperial Valley indicates that vertical drainage is more effective than traditional tile systems in reducing artesian water levels and the overlying clay soil moisture, and should over time also reduce the salinity of these soils. The cost of a widely spaced drainage well system appears comparable to "splitting" existing drainlines.

Drainage systems are commonly used in arid irrigated regions to promote crop growth by controlling water-table depth, root zone salinity and soil aeration. The Imperial Valley is extensively drained with both open ditches and lateral (tile) drainage systems that are designed to provide relief from shallow water tables. As a result of low permeability, the lateral drainage systems are relatively ineffective in many of the heavy clay soils that make up over $40 \%$ of the irrigated valley (California Agriculture, May-June 1988). Improving such drainage systems may be unfeasible because of the high costs associated with narrowly spaced drainlines. Nevertheless, during the past 3 decades growers in parts of the valley have "split" the original drain spacing in the clay soils in an effort to improve their efficacy, with little documentation that any improvement was achieved.

In our previous work in the area, we found that the poor performance of lateral drainage systems may be exacerbated by shallow fine-sand aquifers, which are a source of artesian water into the clay. Lateral drainage systems were not designed for these conditions, although several drainage studies from the 1940s and 1950s describe the widespread occurrence of the finesand aquifer. This artesian water results in relatively high soil moisture in the clay soil profile, and in progressive salinization of the root zone.

Although they have been only briefly considered as an alternative in the Imperial Valley, vertical drainage systems have been successfully installed in other semiarid to arid regions such as the Patterson area of Stanislaus County, the Salt River Valley of Arizona, and parts of the Red River Valley of North Dakota. This report evaluates the potential for and feasibility of developing a shallow vertical or well drainage system for the clay soils overlying fine-sand aquifers in the Imperial Valley as a means of reclaiming or improving these soils for crop production. We also compare the costs associated with lateral and well drainage systems and consider some of the benefits and drawbacks associated with each system.

\section{Imperial Valley setting}

The Imperial Valley is a highly stratified alluvial valley with an arid climate characterized by an average annual rainfall of approximately 3 inches, high summer temperatures, low relative humidity and abundant sunshine. The near-surface layers to depths of 300 feet alternate between sands, silts and clays that interfinger and are cross-bedded in formation. Soil boring by the USGS near the city of El Centro indicates that the silty clay and clay surface soils of the area are underlain by sands at depths rang- 